\title{
2001-2021, duas décadas da Brigada Nacional de Teatro do MST Patativa do Assaré: ressonâncias, desafios e interfaces com o trabalho teatral da Educação do Campo
}

Rafael Litvin Villas Bôas ${ }^{1}$

${ }^{1}$ Universidade de Brasília - UnB. Licenciatura em Educação do Campo / Faculdade UnB Planaltina. Área Universitária 01, Vila Nossa Senhora de Fátima. Planaltina - DF. Brasil.

Autor para correspondência/Author for correspondence: rafaelfup@unb.br

RESUMO. O artigo analisa a experiência de duas décadas de atuação da Brigada Nacional de Teatro do MST em comunidades camponesas de diversos estados brasileiros, por meio das metodologias da observação participante, da revisão bibliográfica e da pesquisa qualitativa $O$ trabalho evidencia as tradições do teatro político e popular que ensejam a experiência teatral do MST. Um dos resultados da pesquisa é destacar que a peculiar dinâmica de produção e circulação da Brigada teve desdobramentos em universidades públicas, nas Licenciaturas em Educação do Campo, demonstrando o potencial de construção de uma cultura política contra-hegemônica.

Palavras-chave: teatro do oprimido, MST, cultura política, educação do campo. 


\title{
2001-2021, two decades of the National Theater Brigade of the MST Patativa do Assaré: resonances, challenges and interfaces with the theatrical work of Rural Education
}

\begin{abstract}
The article analyzes the experience of two decades of work by the MST National Theater Brigade in peasant communities in several Brazilian states, through the methodologies of participant observation, literature review and qualitative research. The work highlights the traditions of popular and political theater that give rise to the theatrical experience of the MST. One of the results of the research is to highlight that the peculiar dynamics of production and circulation of the Brigade had consequences in public universities, in the Degrees in Rural Education, demonstrating the potential for building a counter-hegemonic political culture.
\end{abstract}

Keywords: theater of the oppressed, MST, political culture, rural education. 


\section{1-2021, dos décadas de la Brigada Nacional de Teatro del MST Patativa do Assaré: resonancias, desafíos e interfaces con el trabajo teatral de Educación del Campo}

RESUMEN. El artículo analiza la experiencia de dos décadas de trabajo de la Brigada Nacional de Teatro MST en comunidades campesinas de varios estados brasileños, a través de las metodologías de observación participante, revisión de literatura e investigación cualitativa. El trabajo destaca las tradiciones del teatro popular y político que dan origen a la experiencia teatral del MST. Uno de los resultados de la investigación es resaltar que la peculiar dinámica de producción y circulación de la Brigada tuvo consecuencias en las universidades públicas, en los Grados en Educación Rural, demostrando el potencial para construir una cultura política contra hegemónica.

Palabras clave: teatro del oprimido, MST, cultura política, educación del campo. 


\section{Introdução}

Em 2001 teve início uma parceria entre o Movimento dos Trabalhadores Rurais Sem Terra (MST) e o Centro do Teatro do Oprimido do Rio de Janeiro (CTO-RJ) com o propósito de formação de multiplicadores do Teatro do Oprimido para atuação nos territórios de acampamento e assentamento da reforma agrária organizados pelo MST em vinte e quatro estados brasileiros. O objetivo da pesquisa é analisar o saldo estético, político e organizativo desta experiência de duas décadas de teatro em comunidades camponesas brasileiras, considerando os limites, avanços e desafios da dinâmica de produção e circulação teatral engendrada por meio da experiência em curso. Por meio do emprego das metodologias da pesquisa qualitativa, da observação participante e da revisão bibliográfica o artigo pretende demonstrar que a experiência em questão desenvolveu uma práxis que produziu uma cultura política contra-hegemônica.

A memória da experiência abordada no trabalho foi construída por militantes do MST que fizeram e, em alguns casos, ainda fazem parte dos coletivos formados nos estados, por meio de trabalhos monográficos de conclusão de cursos de graduação - produzidos majoritariamente nas primeiras turmas da Licenciatura em Educação do Campo da Universidade de Brasília - ou especialização, e de artigos. Os dois volumes do livro "Teatro e Transformação Social” (MST, 2007) reúnem parte das peças produzidas pelos grupos formados, e pelo elenco de multiplicadores que trabalhou diretamente com Augusto Boal e com os curingas do CTO-RJ em cinco etapas de formação, que ocorreram entre 2001 e 2005, com cerca de dez a quinze dias por etapa, somando o total de trezentas horas de formação dos cerca de trinca curingas militantes do MST que, por sua vez, construíram como resultado da parceria mais de quarenta grupos de teatro em territórios camponeses de acampamentos ou assentamentos do MST. Ao todo foram publicadas dezenove peças dos grupos ligados a Brigada Nacional nos dois volumes do livro "Teatro e transformação social". De acordo com Estevam, atual coordenador da Brigada Nacional de Teatro do MST Patativa do Assaré:

Uma ampla produção dramatúrgica foi realizada pelos militantes do movimento, com peças abordando nossa formação colonial, as lutas camponesas, negras e indígenas, questões de gênero e raciais, problemáticas ambientais e do agronegócio, os impactos destrutivos do capitalismo e do imperialismo. A intervenção teatral mais significativa do MST foi realizada na Marcha 
Nacional de 2005, quando 270 militantes de todo o país participaram de uma encenação do que chamamos de teatro procissão e dezenas de peças foram apresentadas nos mais de vinte dias de marcha para os 12 mil marchantes (2020).

A tradição a qual o teatro do MST se vincula é a do Teatro Político e Popular, assim entendido como aquela oriunda do teatro produzido por segmentos organizados da classe trabalhadora, por coletivos ligados ou financiados por sindicatos, partidos ou movimentos sociais populares, que organizaram dinâmicas de produção e circulação vinculadas às demandas temáticas das massas trabalhadoras. Outras categorias são adequadas para descrever o sentido da ação teatral do MST, como "teatro da militância”, que conforme Garcia (2006) descreve:

Referida nas realidades locais, a militância artística, em especial por meio do teatro, reaviva-se sempre que predomine a intenção explícita de valer-se dos recursos dramáticos e cênicos para servir a uma causa social $\ldots$

No Brasil, historicamente, podem ser exemplos de militância as experiências teatrais do CPC Centro Popular de Cultura da UNE, e os grupos que atuaram na periferia da capital paulista nos anos de 1970, tentando aliar a tradição popular do teatro com o empenho de resistência artística, sob o clima de repressão e censura que caracterizou a década. Do conjunto desses coletivos, destaca-se o grupo União e Olho Vivo, que preserva ainda hoje, desde sua fundação, em 1969, a prática do espetáculo de teatro a serviço dos movimentos populares, no processo de mobilização e organização de suas reivindicações sociais (2006, p. 180).

Com efeito, ocorreram muitos elementos de aprendizado do fazer teatral do MST com a experiência dos grupos e movimentos das décadas de 1960 e 1970. O Coletivo Peça pro Povo, do MST do Rio Grande do Sul, adaptou a peça de agitprop de Augusto Boal "Não tem imperialismo no Brasil" em montagem denominada de "Paga Zé", e com autorização do César Vieira, do grupo Teatro União e Olho Vivo, encenou a peça "Morte aos brancos" conforme descrevem e analisam duas militantes da Brigada Nacional e integrantes do Peça pro Povo (Marques, 2014; Frozzi, 2011).

Cabe destacar que a experiência cultural do MST, no campo da produção de bens simbólicos, é anterior à parceria com o CTO-RJ, e tem início com a assimilação de repertório próprio de canções e poemas de resistência, oriundos de vertentes como a Teologia da Libertação, a tradição de trovadores populares e a influência da produção cultural latino-americana de lutas anti-imperialistas, nacionalistas e revolucionárias como a Revolução Cubana (1959-) e a Revolução Sandinista na Nicarágua (1979-1989). 
Brennand situa nos anos 1970, na tendência da produção cultural que seguiu resistindo à ditadura por meio da produção da arte popular engajada, sem aderir à indústria cultural, uma fonte central de influência para a atuação cultural do MST.

Os movimentos sociais passaram a ter uma produção cultural intensa, compondo músicas e versos, ousando através da arte denunciar e propor novas formas de organização social, porém, quase sem os meios de produção artística. A maior parte desta produção ficou limitada aos seus espaços de atuação, sendo que a reprodução dos produtos, principalmente canções, cartazes e poemas, eram realizados de forma artesanal. Esta produção transitava e era produzida pelos movimentos populares e Comunidades Eclesiais de Base (CEB's), dentro de uma prática comunitária e com o objetivo de contribuir na formação das bases populares. O importante é identificar que muita arte foi produzida, ecoou desde os seringais do Acre, nas áreas de conflito no Bico do Papagaio, nas periferias urbanas, entre indígenas, quilombolas, caboclos e também transpassou os limites do país. Se esta produção artística não foi conceituada como arte pelos setores hegemônicos da indústria cultural, não é isso que importa. A intenção desta produção era e continua sendo uma contribuição nos processos de formação política e cultural para contestação dos padrões hegemônicos, a fim de fortalecer a sustentação de uma proposta contrahegemônica na luta contra o capital. E esta expressão não abdicou e nem se abdica de sua finalidade, da formação de novos sujeitos para a luta pela transformação social. (Brennand, 2017, p. 49).
Também no campo da produção simbólica a tradição da mística do MST assimila legados de tradições socialistas, como o teatro épico, formas estéticas de agitação e propaganda, além da assimilação de tradições religiosas vinculadas às lutas populares. Segundo Costa: "O segundo capítulo do agitprop no Brasil, ainda em andamento, vem sendo escrito pelo MST desde os anos 1980, quando inventou seu próprio teatro de agitprop (a mística) e já tem seu principal teórico, que é Ademar Bogo, autor de "O vigor da mística" (2015, p. 32). Ainda de acordo com Costa, o primeiro capítulo da experiência do teatro de agitprop em território nacional teria ocorrido com 0 Centro Popular de Cultura (CPC) da União Nacional dos Estudantes (UNE), processo interrompido pela ditadura iniciada em 1964. O trabalho teatral e cultural do MST seria, portanto, de acordo com a pesquisadora, um segundo momento de produção de cultura política em perspectiva contra-hegemônica e anticapitalista.

De acordo com Juliana Bonassa Faria, integrante da Brigada e autora de pesquisas sobre a práxis cultural do MST escritas durante a formação da militante em Cuba:

En el caso del MST el teatro ocupó desde el comienzo un importante papel dentro del campo cultural y 
artístico de la organización. Desde las primeras ocupaciones de tierra, se puede detectar la presencia de grupos teatrales que surgían: de manera espontánea; a partir de la colaboración de grupos profesionales simpatizantes de la causa de reforma agraria; o con un carácter puntual, con el mero objetivo de entretener a la comunidad en momentos festivos.

$\mathrm{Al}$ inicio el quehacer teatral tenía un demarcado carácter espontáneo y ayudaba en el agrupamiento de los miembros de las comunidades. Que muchas veces tenían como objetivo utilizar las obras para contar y comprender los hechos de la lucha y el contexto en que éstos se desarrollaban, además de recordar aspectos de la lucha pasada, tal como podemos observar en una de las funciones de la mística. Hay un elemento importante en ese punto, ya que muchas comunidades tenían una fuerte relación con el ala progresista de la Iglesia Católica, donde es conocida la utilización del teatro como instrumento pedagógico de carácter narrativo; y por lo tanto, esa práctica se evidenciaba constantemente tanto en las comunidades Sin Tierra como en las estructuras católicas. (Faria, 2012, p. $65)$.

Desde 1990 começa a ocorrer uma aproximação dos grupos de teatro político com o MST, de forma progressiva, embora não sistemática, por meio de apresentação de peças em assentamentos, acampamentos e encontros do movimento. Participaram desse processo os grupos Companhia do Latão (SP), Companhia Ensaio Aberto (RJ), Ói Nóis aqui traveiz (RS), entre outros. O Centro do Teatro do Oprimido (RJ), anteriormente à parceria que deu origem à Brigada Nacional Patativa do
Assaré, desenvolveu uma experiência local em assentamento de Itaguaí (RJ), com o grupo Sol da Manhã, de 1991 a 1997. O curso natural da progressão dessas aproximações foi o estreitamento de laços, quebrando a relação estanque atores/público, por meio da socialização do processo de trabalho, mediante a transferência dos meios de produção da linguagem teatral, em oficinas, seminários, debates, ensaios abertos, leituras dramáticas, etc.

Todavia, foi com a parceria de trabalho de cinco anos entre MST e CTORJ que se consolida um projeto sistemático de formação de multiplicadores das técnicas do Teatro do Oprimido com o objetivo de formar grupos de teatro $\mathrm{e}$ democratizar o trabalho com linguagem teatral em escolas do campo, cursos de formação, brigadas de trabalho de base, etc.

Sendo as formas e métodos do Teatro do Oprimido oriundos da tradição do teatro de agitprop, com essa parceria o MST aprofundava seu vínculo com o legado histórico do Teatro Político e Popular. Segundo Garcia, no verbete sobre Teatro de Agitprop do Dicionário do Teatro Brasileiro: “Ainda entre nós, guarda também clara semelhança e afinidade com o agitprop o Teatro do Oprimido, criado e desenvolvido por Augusto Boal: o teatro 
fórum, o teatro invisível e, antes deles, as experiências com teatro jornal, são todas formas de aproximação e intervenção teatral da realidade inventadas pelos grupos agitpropistas históricos" (2006, p. 18). Nessa perspectiva, Costa destaca:

E tem um sentido - que Ademar Bogo caracterizaria como parte da mística do MST - o CTO ter ajudado o MST a escrever o primeiro capítulo da sua luta na frente teatral, pois há um vínculo profundo entre as formas do Teatro do Oprimido e as diversas formas do teatro de agitação e propaganda inventadas pelos socialistas desde o final do século XIX que se multiplicaram durante a revolução soviética e no Brasil foram apenas esboçadas pelo CPC (2015, p. 33).

Augusto Boal, impedido de atuar no teatro profissional, após o acirramento da repressão com o Ato Institucional $n^{\circ} 05$ (AI-5), retoma os vínculos com as classes populares por meio do Teatro do Oprimido, já não mais tendo à disposição o aparelho teatral e o elenco profissional como meio, e a peça como fim. Parte da experiência de opressão dos explorados e elabora o material cenicamente de modo que a população possa participar e intervir no debate, discutindo táticas de intervenção na cena e na realidade que, em geral, dependem da organização coletiva e do fortalecimento do poder popular, focos de acumulação que as ditaduras latinoamericanas se encarregaram de destruir.
Nessa perspectiva, na medida em que situamos o Teatro do Oprimido como elo em um processo organizativo em reconstrução deixamos de ter como fim a crítica de seus resultados formais, das peças construídas com seus potenciais e limites. O centro não é mais a obra fechada, produto resultante do trabalho do teatro profissional. Para o primeiro plano ascende a experiência das pessoas, mediadas e transformadas em cena pelas técnicas teatrais. Trata-se de articulação singular entre teatro político e educação popular, em resposta ao silenciamento e à cultura da inação imposta pela ditadura militar. Boal não pretendia apenas fazer teatro para o MST, mas, nos termos da educação popular, se dispôs a fazer teatro com o MST, se propondo a dar forma teatral aos problemas do Movimento, e transferindo as técnicas para que elas fossem usadas de acordo com as demandas e interesses da Organização. Cabe destacar a coerência política da atitude se comparada à proposta elaborada a partir da radicalização das lutas populares dos anos 1960: o teatro desvencilhado de suas estruturas mercantis, da mediação da produção profissional, da imposição da bilheteria, dos patrocinadores; o teatro inserido organicamente como linguagem integrante do processo de formação dos 
militantes, dos assentados e acampados das comunidades camponesas.

Amplamente utilizado pela professora Marcia Pompeo Nogueira (2015), no contexto brasileiro, a denominação Teatro em Comunidade não se refere a um tipo específico de teatro que é feito em comunidades, mas a diversas formas teatrais que acontecem em contextos comunitários, abrangendo variadas instâncias de interação entre artistas e comunidades. A denominação "Teatro em Comunidade" possui vasta abrangência, referindo-se a práticas teatrais que envolvem, em alguma medida, a participação de pessoas, histórias de vida, ligações com os territórios, engajamento em causas sociais e culturais de grupos específicos, além de um compromisso com o caráter coletivo dos processos de criação. Nogueira (2009) destaca três categorias do teatro em comunidade: teatro para comunidades - onde atores apresentam um espetáculo teatral sem conhecer a realidade da comunidade; Teatro com comunidades modelo em que atores investigam uma comunidade para criar um trabalho teatral; e o teatro por comunidades - que inclui as próprias pessoas da comunidade no processo de criação teatral.

O teatro produzido pelo MST constitui, portanto, uma experiência vigorosa de ação teatral com comunidades camponesas, por comunidades camponesas e a partir dos temas e questões de interesse para essas coletividades de integrantes do Movimento dos Trabalhadores Rurais Sem Terra, estejam essas pessoas vivendo em acampamentos, assentamentos ou militando na organização e vivendo em zonas urbanas. Nesse sentido, os temas são os mais variados, conforme destaca Costa no prefácio “Ações contra-hegemônicas exemplares" escrito para o livro da Brigada Nacional Patativa do Assaré:

Boa parte delas mostra os meios de comunicação produzindo mentiras sobre o MST, apenas a versão do latifúndio sobre os enfrentamentos e a justiça como arma adicional da dominação de classe. Outras mostram a escola pública como lugar de transmissão de mentiras de todos os tipos e, pior, como um lugar onde se praticam vários tipos de discriminação, a começar por aquele de que são vítimas as crianças do MST, as sem-terrinha. Tratam ainda da persistência da incompreensão do papel da mulher e do exame crítico das relações de poder no próprio interior do movimento, do papel do imperialismo nos países latinoamericanos e das várias táticas, todas violentas, do latifúndio e do agronegócio na luta encarniçada por seus próprios interesses (Costa, 2007, p. 05).

Boal ensinava a perceber as diversas formas de exploração e discriminação de uma maneira não hierárquica: sem colocar uma forma na frente da outra, necessariamente, ao mesmo tempo em que 
tentava percebê-las todas em perspectiva de conjunto. De modo que lhe interessava, sem distinções, tanto o confronto entre latifúndio e trabalhadores rurais sem terra, quanto a luta entre capital e trabalho, ou entre interesses nacionais versus dinâmica imperialista do capital, ou violência doméstica, ou o racismo, etc. "Como o Teatro do Oprimido trabalha com a construção de peças a partir da experiência dos participantes das oficinas, Boal partia da premissa de que todo problema aparentemente específico pode ser explorado como parte da totalidade" (Villas Bôas, 2013, p. 288).

A partir desse amplo leque de questões abertos pelas peças do elenco da Brigada Nacional em etapas de formação o MST se apropria das técnicas do Teatro do Oprimido, sobretudo, do Teatro Fórum, para tratar do vasto repertório de temas que envolvem as relações de poder e as formas de opressão, como o machismo e a dinâmica do patriarcado, a violência doméstica, o racismo, o abuso de poder daqueles que exercem posições de representação, com interesse de examinar essas relações, discuti-las nas assembleias criadas por meio do Teatro Fórum, e desenvolver táticas de superação desses problemas. Para isso foram criados nos estados cerca de quarenta grupos de teatro, como tarefa delegada por Augusto Boal aos militantes da Brigada Nacional, nas etapas de Tempo Comunidade que intercalavam as etapas de formação no Rio de Janeiro. Cada coletivo desenvolveu seu próprio repertório de peças, a partir de demandas das comunidades dos territórios camponeses do MST, com, por e a partir do interesse dessas comunidades e da concepção estratégica de transformação social defendida pelo MST.

Portanto, as questões do modo de vida tornaram-se temas para o teatro do MST, fazendo com que o teatro contribuísse para a politização do debate sobre assuntos que até a primeira década do século XXI ainda encontravam resistência na discussão sobre a estratégia revolucionária das organizações populares. Temas como a luta contra o racismo e o debate sobre o feminismo eram, com frequência, vistos como temas secundários diante da pauta econômica, e era comum a alegação de que o debate sobre essas temáticas poderia cindir os elos de classe entre a classe trabalhadora. Todavia, o que se presencia nas seções de Teatro Fórum é o exato oposto: as cenas desencadeiam debates sobre a presença das diversas formas de discriminação no cotidiano dos espaços da classe trabalhadora; os depoimentos de pessoas que se reconheciam nos gestos opressores gera comprometimento no enfrentamento ao 
tema, na medida em que as pessoas decidem voluntariamente se expor, narrar suas experiências pessoais e torna-las públicas, por exemplo, com homens assumindo que já cometeram violências domésticas e avaliando negativamente essas ações; a discussão sobre cenas de racismo, por exemplo, retiraram da invisibilidade do debate no ambiente militante o debate sobre as relações entre classe, raça e gênero e colaboraram para que essas questões fossem assimiladas no programa estratégico de formação, e medidas concretas de enfrentamento às múltiplas formas de exploração e opressão fossem tomadas; o posicionamento coletivo das mulheres sobre as violências do regime patriarcal ampliou o vocabulário da militância e das famílias acampadas e assentadas sobre as formas de machismo, para além da violência física, e muitas vezes o teatro foi meio de informação, formação e organização social no enfrentamento contra essas estruturas de poder constituintes de nossa experiência coletiva como sociedade.

Se comparada com a tradição de boa parte das organizações democráticas brasileiras, partidárias, sindicais ou de movimentos populares, a proposta metodológica do Teatro do Oprimido apresenta novidades consideráveis à dinâmica da cultura política, pois permite não apenas a escuta dos anseios populares, mas o fortalecimento dos mecanismos do poder popular, na medida e que se faz necessário que os canais entre base e direção das organizações esteja aberto de forma permanente.

$\mathrm{Na}$ medida em que os grupos se multiplicavam pelos estados foram ampliadas as parcerias com grupos locais, pautadas pela demanda de apropriação dos meios de produção das linguagens artísticas. No livro lançado em 2007 pela Brigada Nacional de Teatro do MST Patativa do Assaré "Teatro e transformação social" foi apontada a percepção que estava em andamento a construção de uma espécie de sistema interno de produção e circulação teatral, em articulação com coletivos parceiros, organizando uma dinâmica particular de autores, obras, coletivos e público. De acordo com Brennand:

Um fator que nos chama a atenção, é que a atuação da Brigada Patativa do Assaré começou a esboçar uma espécie de sistema interno de socialização entre os grupos produtores de peças no âmbito do MST, fazendo que as mesmas itinerassem dentro do próprio Movimento e também fora dele. Nas atividades nacionais do Movimento, alguns grupos de teatro ou seus representantes encontravam-se, compartilhavam experiências e realizavam apresentações. No retorno aos seus estados os grupos replicavam as peças nos acampamentos e assentamentos de 
seus respectivos estados (2017, p. 120).

Um exemplo desse processo de produção e circulação interna ocorreu na Marcha Nacional pela Reforma Agrária e Justiça Social, entre Goiânia a Brasília, em 2005, com mais de doze mil marchantes que percorreram o trajeto entre as capitais de Goiás e do Brasil em dezessete dias: “... a peça "A Bundade do patrão" foi apresentada pelo coletivo Peça pro Povo (RS), pela Brigada Estadual de Cultura Filhos da Terra (MS) e pela Brigada de Agitprop [Semeadores] do Gabriela Monteiro (DF). Também na marcha, a peça "Exploração do Trabalho" foi apresentada por cinco elencos, e outros dois elencos apresentaram uma adaptação da mesma peça intitulada "Como fazendeiro sofre" (MST, 2007, p. 13).

A linguagem teatral e a metodologia do Teatro do Oprimido foram democratizadas no MST por meio da demanda de formação de diversos setores, como Educação, Formação, Saúde, Direitos Humanos, Comunicação e Frente de Massa. A quantidade e qualidade dos grupos formados não é o único termômetro que permite aferir a capilaridade orgânica e territorial dos trabalhos, na medida em que muitos educadores e educadoras militantes trabalham com o teatro nas escolas do campo, seja formando grupos permanentes, seja utilizando de forma pedagógica e estética a linguagem teatral em suas aulas, e no processo de formação inter e transdisciplinar.

Com a guinada conservadora da história política recente do país, uma série de medidas de criminalização do MST e demais movimentos populares de massa tiveram impacto nas dinâmicas de formação, produção e circulação das brigadas artísticas. Por exemplo, sem os pontos de cultura em territórios camponeses, que estavam em processo de expansão, com forte apoio do programa Cultura Viva do Ministério da Cultura, nas gestões de Gilberto Gil e Juca Oliveira, nos governos do presidente Lula da Silva (Brennand, 2017), a Rede Cultural da Terra - rede formada para fortalecer e integrar a produção cultural do campo por meio do fomento a criação e manutenção de pontos de cultura em territórios camponeses - encontrou dificuldades para manter o calendário de encontros de formação, festivais, seminários, que garantiam o processo de circulação dos trabalhos dos coletivos e conferiam vivacidade ao sistema teatral em construção.

Todavia, cabe destacar, conforme avaliação de pesquisadoras militantes do Coletivo de Cultura do MST, os aspectos que ressaltam as colaborações da Brigada 
de Teatro para o fortalecimento de uma cultura política contra-hegemônica. De acordo com Marques, que exerceu a função de coordenadora regional da Brigada no Sul do país e coordenou o coletivo Peça pro Povo:

A Brigada conseguiu sinalizar concretamente para uma perspectiva de produção contra-hegemônica produzindo coletivamente, quebrando com a lógica do espetáculo, em um processo de autogestão, sem um diretor/a, de maneira que todos tinham o domínio do todo: desde a dramaturgia, a apresentação, dos bastidores até os comentários posteriores à apresentação. $\mathrm{O}$ processo de produção (técnicas, teoria e prática teatral) foi sendo apropriado, sem que o foco ficasse unicamente no produto: "a peça", a ênfase foi conferida ao processo de produção. Percebíamos no desenvolver das produções algumas contradições, para tanto trabalhávamos na estrutura formal das peças para que a forma de representação estivesse de acordo com o que estávamos debatendo (Marques, 2014, p. 66).

Faria, militante que exerceu a função de coordenação nacional da Brigada Patativa do Assaré avalia que essa frente "fue una gran propulsora del debate $y$ principalmente a partir de la práctica sobre la capacidad transformadora del arte, principalmente por medio del teatro. Miles de militantes del MST, de una manera u otra, participaron de ese proceso y a partir de sus planteamientos ayudaron a insertar el quehacer artístico como una práctica tan militante como las de los demás sectores del Movimiento". (2012, p. 82).

Quanto aos limites, há sete anos atrás Marques demarcava em sua dissertação os seguintes aspectos que se mantém como problema, em 2021: "um dos principais é a dificuldade de continuação de um processo de formação permanente; a falta de continuidade dos encontros nacionais, e formações específicas com a Brigada Patativa do Assaré, também se configuram como um grande limite; o fato da maioria dos nossos grupos mais fortes não existirem mais também foi um fator limitante da continuidade" (2014, p. 71). Por sua vez, Faria destaca: "Otro elemento importante en la imposibilidad de secuencia del trabajo iniciado se da por la dificultad de comprensión por parte del conjunto y de las instancias del movimiento sobre el propio papel del arte en el contexto de la lucha política y el proyecto estratégico del MST" (2011, p. 84).

As mudanças políticas, econômicas e culturais pelas quais o país atravessou nos últimos anos impactaram a dinâmica organizativa e formativa do MST. Não mais foi possível realizar etapas de formação nacionais com novas turmas de militantes de todos os estados, os grupos que tiveram atuação mais intensa não existem mais, por diversos motivos, dentre 
os principais estão o fluxo migratório do campo para a cidade em busca de condições de estudo e trabalho, que desagrega os elencos, a distância em um mesmo território de assentamento, entre os integrantes de um mesmo grupo, que encontram dificuldades logísticas de transporte para os ensaios cotidianos, a diminuição das oportunidades para que os grupos circulem com seus repertórios...

Entretanto, e por fim, ocorreram desdobramentos da ação teatral do MST que cabem destacar, em breves e significativos exemplos.

O primeiro deles, é que a organização em forma de brigada dos militantes que atuam com teatro ensejou no Coletivo Nacional de Cultura do MST a organização das demais linguagens igualmente em brigadas ou frentes: a música está organizada na Brigada João do Vale, as artes plásticas na Brigada Cândido Portinari, o audiovisual na Brigada Eduardo Coutinho e a literatura na Frente Palavras Rebeldes. Evidentemente, militantes com múltiplas vocações e com aptidões trabalhadas em diversas linguagens atuam nos estados, em escala local ou regional, de forma articulada.

Ou seja, a divisão das linguagens em brigadas e frentes nacionais não ocorreu para alienar o processo produtivo, mas para intensificar os processos formativos de acordo com as demandas específicas de cada linguagem. Todavia, nos estados, as brigadas culturais costumam trabalhar de forma integrada com todas as linguagens. Conforme Brennand:

No processo organizativo estadual, as Brigadas buscam abarcar todas as linguagens artísticas com o intuito de se constituir como o "braço artístico" do MST, seja nos territórios conquistados, seja na disputa política na luta pela Reforma Agrária, nas lutas com outros setores organizados, alinhados com a táticas e estratégias do Movimento (Op. Cit, p. 118).

O segundo exemplo, resultante do primeiro, é o trabalho integrado de militantes das brigadas Patativa do Assaré, Frente Palavras Rebeldes, Brigada Eduardo Coutinho e Brigada João do Vale e de coletivos teatrais de três estados Banzeiros (PA), Terra em Cena (DF) e Dolores (SP) - em processos como a participação do MST na Feira Virtual de Opinião realizada pelo Instituto Augusto Boal, a partir da questão "Que pensa você do Brasil de hoje?", , que foi ao ar em 10 de outubro de 2020 e está disponível no canal do youtube do Instituto Augusto Boal, desde essa data. Nessa intervenção a “opinião" do Movimento foi construída por meio de roteiro em que o elemento estruturante foi a peça Mutirão em Novo Sol, de Nelson Xavier e Augusto Boal, escrita em 1961 e remontada posteriormente pelo MST, desde 2008, nos 
cursos da Educação do Campo, nos cursos de Artes do Programa Nacional de Educação da Reforma Agrária (Pronera), e nos cursos internos de formação do MST e da Via Campesina.

A peça teve uma versão gravada para rádio pela turma de Comunicação e Cultura de ensino médio do Iterra, a Brigada de Agitprop Semeadores do MST/DFE (Sousa, 2013) fez algumas montagens da versão adaptada, no assentamento Gabriela Monteiro, no Instituto Federal de Brasília e no campus de Planaltina da UnB e, em agosto de 2012, em Brasília, militantes da Brigada Nacional Patativa do Assaré e do Coletivo Terra em Cena da UnB apresentaram a adaptação da peça no Encontro Unitário dos Povos do Campo, das Águas e da Floresta, para cinco mil camponeses, quilombolas, indígenas, ribeirinhos e pescadores.

Além dessa versão circulada em 2020 para a Feira Virtual de Opinião, o MST, por meio das Brigadas de Teatro e de Audiovisual, em parceria com o Coletivo Terra em Cena, e com integrantes dos elencos da Cia Burlesca, da Escola de Teatro Político e Vídeo Popular do DF e de integrantes de acampamentos e assentamentos do MST do Distrito Federal está finalizando um filme longa metragem chamado "Mutirão em Novo Sol: a retomada" que deverá circular primeiro por festivais e, posteriormente, nas redes sociais do MST, em 2021. Portanto, embora no saldo orgânico a quantidade de grupos hoje seja menor do que nos tempos em que contávamos com políticas culturais a favor da classe trabalhadora, é possível notar o aumento da capacidade de produção de bens simbólicos, com militantes formados e capacitados em diversas linguagens trabalhando de forma unificada.

E, por fim, o terceiro exemplo é o desdobramento do trabalho teatral do MST em algumas universidades públicas brasileiras, sobretudo, aquelas que ofertam a Licenciatura em Educação do Campo com área de habilitação em Linguagens, como a Universidade de Brasília (Bastos et all; 2011), a Universidade Federal de Minas Gerais (Carvalho et all, 2016) Universidade Federal de Tocantis (UFT), a Universidade Federal do Piaú́ e a Universidade Federal do Sudoeste do Pará (Unifespa). As práticas artísticas desenvolvidas pelo MST e demais movimentos camponeses e quilombolas não são apenas estudadas como objetos de pesquisa, pelo contrário, são constituintes da práxis político pedagógica e cultural desses cursos, colaborando para moldagem dos projetos político pedagógicos dos cursos, para o desenho dos programas e 
projetos de extensão e colaboram para a ampliação das linhas de pesquisa dos cursos de graduação e pós-graduação.

Na Universidade de Brasília, o Coletivo Terra em Cena é, ao mesmo tempo, um programa de extensão e um grupo de pesquisa e a forma como ele atua é semelhante ao método de formação e multiplicação que a Brigada Nacional de Teatro do MST aprendeu com Augusto Boal e o CTO-RJ (Rocha et al., 2015; Villas Bôas et al., 2020; Pereira et al., 2019). Outro fator que cabe destacar é que, tal como ocorreu no MST, na Licenciatura em Educação do Campo da UnB a experiência de trabalho com teatro em comunidades e territórios camponeses precedeu e estimulou a organização do trabalho com a linguagem audiovisual, e passou a estabelecer conexões produtivas em diversos experimentos, tais como vídeos, webseries como "A farsa" produzida pela companhia Estudo de Cena (SP), programas de TV como o "Revoluções" do Coletivo Terra em Cena, documentários e filmes de ficção (Villas Bôas \& Canova, 2019).

Além disso, a práxis teatral do MST e a articulação do Movimento com territórios e comunidades camponesas, com universidades, coletivos de teatro e vídeo político e popular e grupos de pesquisa se tornou um fator estruturante da
Rede de Escolas de Teatro e Vídeo Político Popular Nuestra América, constituída em 2017, que integra um total de dez escolas sendo sete em estados brasileiros, duas na Argentina e uma na Espanha (Villas Bôas \& Estevam, 2020).

Por fim, duas décadas depois de iniciado o trabalho sistemático de formação e multiplicação da linguagem teatral por meio da Brigada Nacional de Teatro do MST Patativa do Assaré segue o processo de expansão das articulações, sendo permanente o desafio de retomar em escala massiva e com qualidade estética, técnica e política o processo de enraizamento em territórios e comunidades camponesas, quilombolas e escolas do campo. As comemorações do centenário de Paulo Freire, em 2021, e dos noventa anos de Augusto Boal, são ocasiões oportunas para refletirmos sobre as articulações entre a Pedagogia do Oprimido e o Teatro do Oprimido enquanto proposições teóricas e metodológicas instituintes de uma práxis contra-hegemônica ainda não elevada à máxima potência pelas organizações populares, pelas universidades, escolas e pelas políticas educacionais brasileiras. Cabe a nós, trabalhadores da cultura, educadores populares, militantes, intelectuais, integrantes de coletivos, escolas, redes, movimentos e partidos, mantermos em pauta não apenas a reflexão 
sobre a memória, sobre o legado, mas conectar os elos que ligam os aprendizados com as derrotas do passado com o planejamento estratégico do presente para que, na ascensão de um movimento socialista que possa se contrapor ao neofacismo que atualmente governa o país, essa práxis possa fazer parte de uma cultura política outra, radicalmente democrática e popular.

\section{Referências}

Bastos, M., Villas Bôas, R., Corrêa, A., Castro, D., Hess, B., \& Borges. (2011). Estética e Educação do Campo: movimentos formativos na área de habilitação em Linguagens da LEdoC. In Molina, M., \& Sá, L. (Orgs.). Licenciaturas em Educação do Campo: registros e reflexões a partir das experiências piloto (pp. 179-210). Autêntica Editora.

Brennand, E. M. (2017). "Enquanto governa a maldade, a gente canta a liberdade". Coletivo de Cultura do MST: Caminhos para a criação de uma cultura contra-hegemônica (Dissertação de Mestrado). Universidade Estadual Paulista, São Paulo. Recuperado de https://repositorio.unesp.br/handle/11449/1 $\underline{53343}$

Carvalho, C. A., \& Martins, A. A. (2016). Práticas artísticas do campo. Autêntica Editora.

Costa, I. C. (2015). O agitprop e o Brasil. In Costa, I. C., Estevam, D., \& Villas Bôas, R. L. (Orgs.). Agitprop: cultura política (pp. 19-34). Expressão Popular.
Costa, I. C. (2007). Ações contrahegemônicas exemplares. In Teatro e transformação social. Cepatec.

Estevam, D. (2020). Teatro e luta de classes. Recuperado de https://mst.org.br/2020/03/27/teatro-e-lutade-classes/

Faria, J. B. (2011). Caminos y descaminhos en la construcción de uma práxis cultural emancipadora. Un registro crítico del desarrollo del Colectivo Nacional de Cultura del Movimiento Sin Tierra de Brasil de 1996 - 2006 (Monografía). Facultad de Humanidades, Santiago de Cuba.

Frozzi, M. L. (2011). Teatro e Formação: a experiência do grupo Peça pro Povo (Monografia de Conclusão de Curso). Universidade de Brasília, Planaltina; Iterra, Veranópolis.

Garcia, S. (2006). Militância (Teatro da) Agitprop (Teatro de). In Guinsburg, J., Faria, J. R., \& Lima, M. A. (Orgs.). Dicionário do Teatro Brasileiro: temas, formas e conceitos (pp. 17-18, 180). São Paulo: Perspectiva; Sesc.

Marques, L. M. A. (2014). Trajetória Política e Estética da Brigada Nacional de Teatro do MST Patativa do Assaré (Monografia de Especialização). Universidade de Brasília, Brasília.

MST, Coletivo Nacional de Cultura. (2005). Caderno das Artes $n^{\circ}$ 01: Teatro. São Paulo: MST.

MST, Coletivo Nacional de Cultura. (2007). Teatro e transformação social. Cepatec.

Nogueira, M. P. (2009). Teatro e comunidade. In Florentino, A., \& Telles, N. (Orgs.). Cartografias do Ensino do Teatro (pp. 172-183) Edufu. https://doi.org/10.7476/9788570785183.001 $\underline{8}$ 
Nogueira, M. P. (2015). Um olhar sobre o teatro em comunidades no Brasil. In Cruz, H. (Org.). Arte e comunidade (pp. 01-556). Fundação Calouste Gulbenkian.

Villas Bôas, R. L., \& Pereira, K. A. (2019). Formação estética e organização social: teatro na Licenciatura em Educação do Campo. Conhecer: Debate Entre $O$ Público E O Privado, 9(23), 63-93. https://doi.org/10.32335/2238$\underline{0426.2019 .9 .23 .1041}$

Villas Bôas. R. L., Rocha. E.N., Pereira, M.P., \& Borges. A. R. (2015). Teatro Político, Formação e Organização Social. Outras Expressões.

Villas Bôas, R. L. (2019). CPC e MST: formas e dinâmicas produtivas do teatro político brasileiro em dois tempos históricos. Sala Preta, 19(1), 150-162. https://doi.org/10.11606/issn.22383867.v19i1p150-162

Villas Bôas, R., Silva, A. G., Rocha, E. N..., \& Pereira, K. A. (2020). Perspectivas de pesquisa na área de linguagens do curso da LEdoC/UnB e no grupo de pesquisa e programa de extensão Terra em Cena (FUP/UnB). In Sousa, J. G. (Org.). Educação do Campo e pesquisa educacional: sujeitos, saberes e práticas educativas (s./p.). Palmas: EDUFT.

Villas Bôas, R. (2013). MST conta Boal: do diálogo das Ligas Camponesas com o Teatro de Arena à parceria do Centro do Teatro do Oprimido com o MST. Revista do Instituto de Estudos Brasileiros, 57, 277-298.

http://dx.doi.org/10.11606/issn.2316-

901X.v0i57p277-298

Villas Bôas, R., \& Canova, F. (2019). Quando Camponeses Entram em Cena: trabalho teatral do MST e a interface com a linguagem audiovisual. Revista Brasileira de Estudos da Presença, 9(4), 01-29. https://doi.org/10.1590/2237-266091022 $\frac{\text { Recuperado }}{\mathrm{i}}$
https://www.youtube.com/watch?v=haxJldUCmuo
\&list=UUYEckoSBl5XaGHx1HnEwUSg. Acesso
em 04/05/2021.

Informações do Artigo / Article Information

Recebido em : 08/06/2021

Aprovado em: 25/08/2021

Publicado em: 30/09/2021

Received on June 08th, 2021

Accepted on August 25th, 2021

Published on September, 30th, 2021

Contribuições no Artigo: O autor foi o responsável por todas as etapas e resultados da pesquisa, a saber: elaboração, análise e interpretação dos dados; escrita e revisão do conteúdo do manuscrito e; aprovação da versão final publicada.

Author Contributions: The author was responsible for the designing, delineating, analyzing and interpreting the data, production of the manuscript, critical revision of the content and approval of the final version published.

Conflitos de Interesse: O autor declarou não haver nenhum conflito de interesse referente a este artigo.

Conflict of Interest: None reported.

Avaliação do artigo

Artigo avaliado por pares.

Article Peer Review

Double review.

Agência de Fomento

Não tem.

Funding 
No funding.

\section{Como citar este artigo / How to cite this article}

APA

Villas Bôas, R. L. (2021). 2001-2021, duas décadas da Brigada Nacional de Teatro do MST Patativa do Assaré: ressonâncias, desafios e interfaces com o trabalho teatral da Educação do Campo. Rev. Bras. Educ. Camp., 6, e12410. http://dx.doi.org/10.20873/uft.rbec.e12410

ABNT

VILLAS BÔAS, R. L. (2021). 2001-2021, duas décadas da Brigada Nacional de Teatro do MST Patativa do Assaré: ressonâncias, desafios e interfaces com o trabalho teatral da Educação do Campo. Rev. Bras. Educ. Camp., Tocantinópolis, v. 6, e12410, 2021. http://dx.doi.org/10.20873/uft.rbec.e12410 